\title{
The potential anti-cancer effects of melatonin on breast cancer
}

\author{
Naba Kumar Das (1), Saptadip Samanta*(1) \\ Department of Physiology, Midnapore College, Midnapore 721101, Paschim Medinipur, West Bengal, India
}

*Correspondence: Saptadip Samanta, Department of Physiology, Midnapore College, Raja Bazar Main Road, Midnapore 721101, Paschim Medinipur, West Bengal, India. saptadip174@gmail.com

Academic Editor: Lindsay A. Farrer, Boston University School of Medicine, USA

Received: October 5, 2021 Accepted: January 4, 2022 Published: February 25, 2022

Cite this article: Das NK, Samanta S. The potential anti-cancer effects of melatonin on breast cancer. Explor Med. 2022;3:112-27. https://doi.org/10.37349/emed.2022.00078

\begin{abstract}
Melatonin is the primary hormone of the pineal gland that is secreted at night. It regulates many physiological functions, including the sleep-wake cycle, gonadal activity, free radical scavenging, immunomodulation, neuro-protection, and cancer progression. The precise functions of melatonin are mediated by guanosine triphosphate (GTP)-binding protein (G-protein) coupled melatonin receptor 1 (MT1) and MT2 receptors. However, nuclear receptors are also associated with melatonin activity. Circadian rhythm disruption, shift work, and light exposure at night hamper melatonin production. Impaired melatonin level promotes various pathophysiological changes, including cancer. In our modern society, breast cancer is a serious problem throughout the world. Several studies have been indicated the link between low levels of melatonin and breast cancer development. Melatonin has oncostatic properties in breast cancer cells. This indolamine advances apoptosis, which arrests the cell cycle and regulates metabolic activity. Moreover, melatonin increases the treatment efficacy of cancer and can be used as an adjuvant with chemotherapeutic agents.
\end{abstract}

\section{Keywords}

Melatonin, breast cancer, cell cycle, apoptosis, chemotherapy

\section{Introduction}

It is well-known that the hormone melatonin has oncostatic effects both in vivo and in vitro conditions in various types of cancers, including breast. Melatonin can disrupt estrogen-mediated cellular pathways, ensuing in a lattice drop of estrogenic stimulus to the breast cancer cells. Studies have shown that sleep and/or circadian disruption, specifically night shift work, chronic jet lag, trans-Mediterranean traveling are correlated with an increased risk of breast cancer development.

Melatonin is an indolamine ( $N$-acetyl-5-methoxytryptamine), identified by Lerner et al. [1] from the mammalian pineal gland. The precursor of melatonin is serotonin, a potent neurotransmitter. The environmental light-dark cycle is the potent regulator of melatonin synthesis. The suprachiasmatic nucleus (SCN) of the hypothalamus receives photoperiodic information and regulates the synthesis and secretion of melatonin through a complex neural connection [2,3]. Melatonin is the modulator of the 
central circadian clock and peripheral clock of the different tissues, including the breast [4]. Many laboratories have focused on the functions of the clock genes and proteins that are involved in cellular activities, including cell survival, cell cycle regulation, proliferation, apoptosis, DNA damage repair, and tumor promotion or suppression [5,6]. With the synchronized output of the central circadian clock in relation to the pineal gland and other peripheral oscillators, melatonin acts as a key role player in the regulation of intermediary metabolism and cancer prevention [7]. Several studies have revealed that circadian rhythm disruption, specifically night shift work is linked with an increased risk of breast cancer [8]. Impaired melatonin level promotes breast, ovarian, prostate, hepatocellular, and other cancers. Melatonin has oncostatic properties that are mediated by induction of apoptosis, arresting the cell cycle, regulation of metabolic activity, and the inhibition of hypoxia-inducible factor $1 \alpha$ (HIF-1 $\alpha$ ) activity [9]. Excessive exposure to estrogen is a key risk factor for breast cancer [10]. Melatonin primarily regulates steroidogenesis and shows anti-gonadal activity.

Numerous studies had revealed that the increased rate of night shift works suppresses melatonin production and increases the risk of estrogenic stimulation for breast cancer development. An inverse correlation has been observed between melatonin and the risk of development of breast cancer. Melatonin levels are low in women with breast cancer [11]. Additionally, maintenance of the light-dark cycle and oral supplementation of melatonin may have a beneficial effect on women who are facing the risk of breast cancer [12]. This review will touch the oncostatic effects of melatonin in breast cancer and its possibilities in cancer treatment.

\section{Synthesis of melatonin}

The pineal gland is the primary site of melatonin synthesis. It begins with the conversion of tryptophan to 5-hydroxy-tryptophan, which is then converted to serotonin, followed by melatonin after methylation (Figure 1) [13]. Melatonin production is increased by induction of the rate-limiting enzyme arylalkylamine $N$-acetyl transferase (AANAT) [14]. The expression of this enzyme is regulated by the exposure of light to the retina. Photoperiod regulates the synthesis and secretion of melatonin. Light exposure in the daytime represses melatonin production, while darkness acts as an inducer. The peak of melatonin production occurs at about 2 a.m. in humans [15]. Alternatively, light-at-night (LAN) inhibits melatonin synthesis [16]. Multiple studies indicated that pinealectomy or circadian disruption can stimulate spontaneous growth and development of tumors, and metastasis of the existing tumors $[17,18]$. In addition, melatonin is also synthesized in extra-pineal organs, including the retina, gastrointestinal tract, skin, lymphocytes, and bone marrow [19].

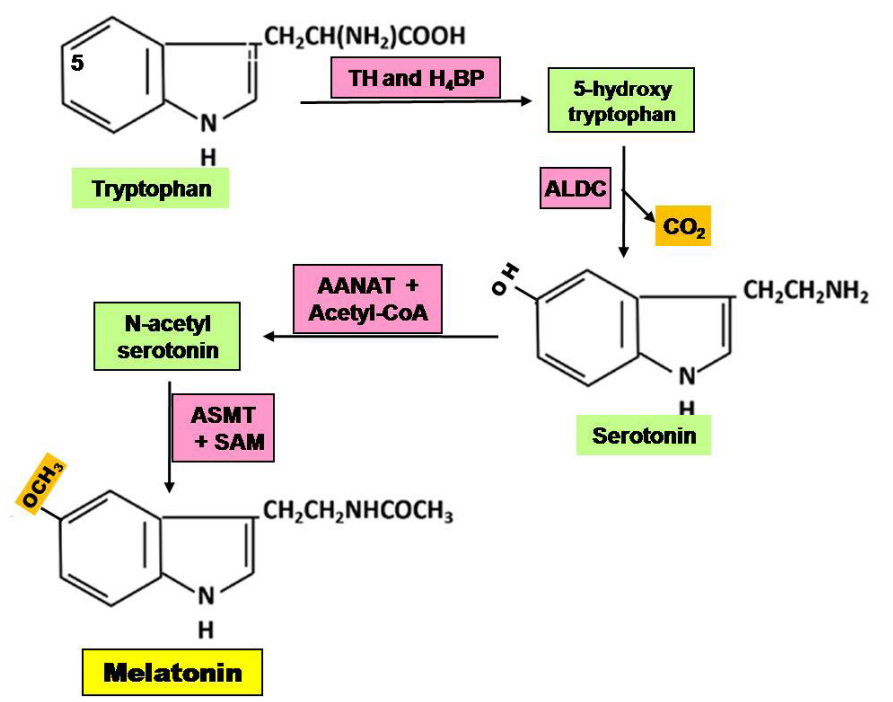

Figure 1. Steps of synthesis of melatonin in pineal gland. ALDC: aromatic L-amino acid decarboxylase; ASMT: acetylserotonin $\mathrm{O}$-methyl transferase; $\mathrm{H}_{4} \mathrm{BP}$ : tetra hydrobiopterin; SAM: $\mathrm{S}$-adenosyl methionine; $\mathrm{TH}$ : tryptophan hydroxylase 


\section{Mechanisms of actions}

Melatonin is a lipophilic compound. Its action is mediated primarily through binding to the cell surface melatonin receptors (MT1, MT2). These are membrane-bound GTP-binding protein (G-protein) coupled receptors (GPCRs). They modulate the activity of the variety of G-proteins, including Gi $\alpha 2$, Gi $\alpha 3$, G $\alpha q$, and $\mathrm{G} \alpha 11[20,21]$. Moreover, melatonin acts directly to the DNA binding nuclear receptors (NRs) [retinoid-related orphan receptor (ROR)- $\alpha$ /isoforms of nuclear receptors of retinoic acid receptor superfamily (RZR)]. In humans and other mammals, the MT1 receptor is encoded by the MTNR1A gene and the MTNR1B gene is responsible for the MT2 receptor [22, 23]. The MT1 receptor inhibits the production of cyclic adenosine monophosphate (cAMP) via pertussis toxin-sensitive inhibitory Gi $\alpha$ proteins [20,24]. Activated MT1 receptor helps in the inhibition of forskolin-stimulated cAMP formation, followed by suppression of protein kinase A (PKA) activity and phosphorylation of the cAMP-responsive element-binding protein (CREB) $[25,26]$. Melatonin-mediated activation of the MT1 receptor has also been involved in the modulation of ion channels in cells [26].

In addition, the MT2 receptor has also been associated with G-proteins to decrease forskolin-activated cAMP production. It modulates cyclic guanosine monophosphate (cGMP) formation and amplifies PKC activity [27, 28]. The MT1- and MT2-mediated melatonin signaling is enhanced by the formation of homo- or hetero-dimmers for the modification of receptor functions and activity $[29,30]$. Furthermore, G-protein-coupled receptor 50 (GPR50), a melatonin-related receptor is incapable to bind with melatonin but can dimerize with MT1 and MT2 receptors that only repress the affinity of MT1 [31]. The activation of the MT1 receptor shows much of melatonin's oncostatic actions, resulting in the net reduction of estrogenic stimulation in estrogen receptor- $\alpha$ (ER- $\alpha$ )-positive MCF-7 human breast cancer cells [32].

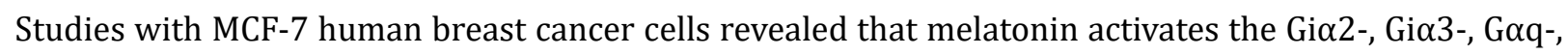
and Ga11-coupled MT1 receptors [33]. MT1 receptor overexpression can enhance the anti-proliferative effect of melatonin on breast cancer cells in both in vivo and in vitro conditions. Application of non-selective MT1 and MT2 receptor antagonists showed reverse effects [30, 34]. Experimental evidence from breast tumor biopsy specimens had revealed that there was a correlation between the MT1 receptor activity and ER- $\alpha$ expression [35]. Besides these, both MT1 positive and triple-negative breast cancers (TNBC) exhibited a lower proliferative rate with smaller tumor size, while MT1 negative TNBC was notably linked with a higher risk of progression of breast cancer [36]. To date, all studies have indicated the MT1 expression with an improved prognosis compared to those with MT1 negative breast tumors [25, 37].

Melatonin can cross the cell membrane due to its lipophilic nature. At the cytosolic site, it binds with the nuclear and mitochondrial proteins to drive a variety of non-receptor-mediated effects in breast cancer cells. Several studies had revealed that melatonin binds to the calmodulin (CaM) receptor, which decreased the sensitivity of adenylate cyclase (AC) [38]. Inactivated AC lowers cAMP levels within cells that can downregulate the activation of PKA, CREB, and p300 co-regulator; the collective effects are attenuation of phosphorylation and trans-activation of different transcription factors and NRs, including ER- $\alpha$ [11].

It had also been reported that melatonin acts as a potent free radical scavenger. The activity is mediated by MT3, a quinine-reductases. The subsequent result is diminution of reactive oxygen species (ROS)-mediated oxidative damage in various tissues, including the breast [39]. In in vitro study, administration of melatonin in ZR-75-1 and MCF-7 breast cancer cells triggered the expression of glutathione and glutathione-S-transferase that decrease tumor cell metabolism and proliferation [25]. Melatonin shows receptor-mediated immunomodulatory effects in the immune system [40] and reduces telomerase activity [41].

\section{Anti-proliferative effects of melatonin on breast cancer cells}

Animal studies and clinical data had revealed that melatonin decreases the occurrence of in vitro tumor cell-induced cancers [11]. It also significantly inhibits the growth of some human breast tumors [25, 42]. Melatonin exerts both anti-proliferative and apoptotic effects in breast cancer cells in multiple ways (Figure 2) [25,43]. The anti-proliferative functions of melatonin are mediated by the activation 
of the MT1 receptor in MCF-7 cells-induced transfection model [34, 44]. Melatonin receptor suppresses ER- $\alpha$-mediated transcriptional activity in ER- $\alpha$-positive breast tumor cells. The arrest of cell cycle and the cell proliferation are mediated by the inhibitory actions on $\mathrm{Ca}^{2+}$ signaling and CaM expression [25], stimulation of p53 expression [45], and p21-gene transcription (Figure 2) [46]. It was reported that blocking of MT1/MT2 receptors in MCF-7 cells showed impaired p53-mediated repairing of DNA damage [47]. This indolamine arrests the cell cycle of breast tumor cells in the gap phase 1 (G1) phase [41], prevents estrogen synthesis by inhibiting aromatase activity [34,48]. Melatonin also suppresses the uptake of linoleic acid (LA) in the tumor cells [49].

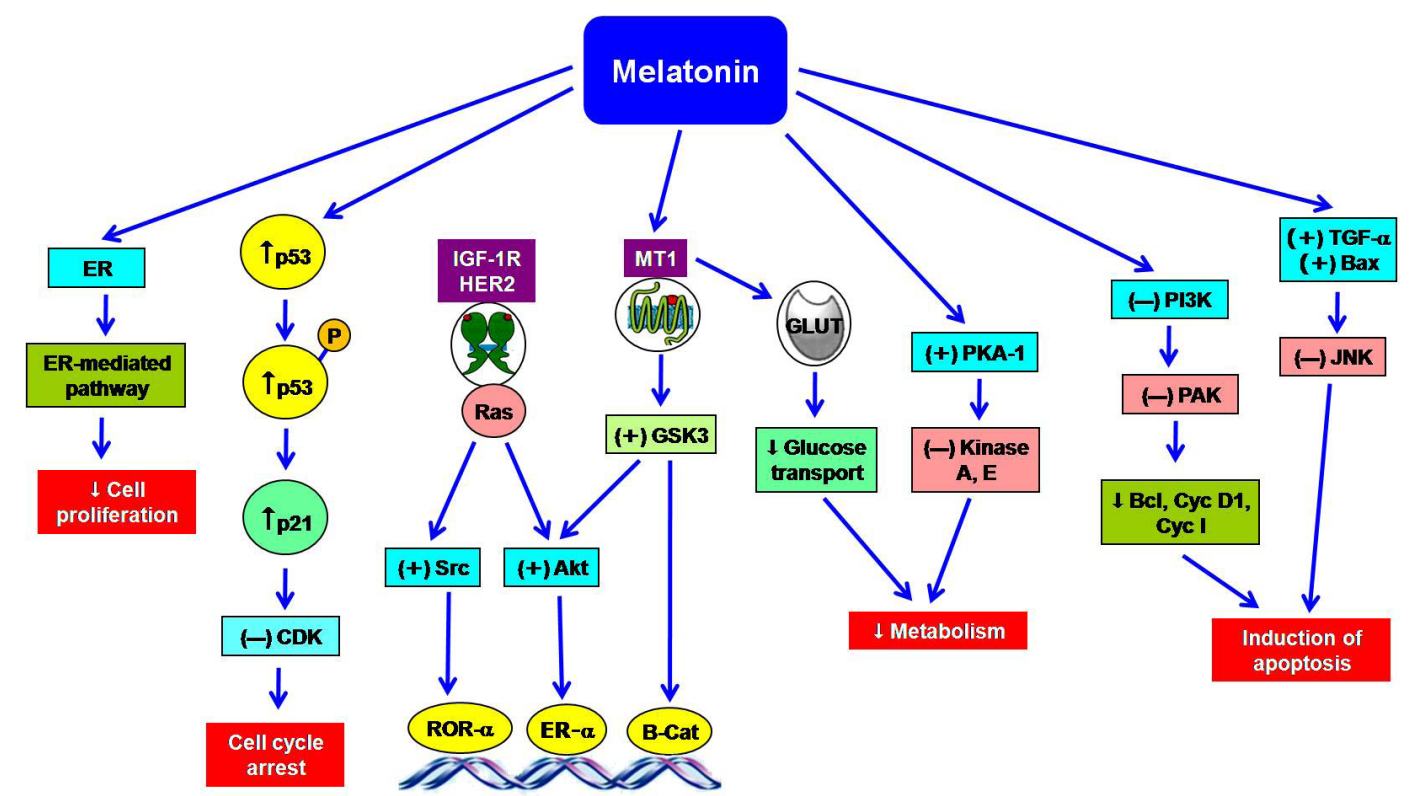

Figure 2. The multiple actions of melatonin in the prevention of breast cancer. $\uparrow:$ increase; $\downarrow$ : decrease; $(+)$ : stimulation; $(-)$ : inhibition; Akt: protein kinase B; Bax: B-cell lymphoma-2 associated X protein; Bcl: B-cell lymphoma; B-Cat: beta catenin; CDK: cyclin dependent kinase; Cyc I: cyclin I; Cyc D1: cyclin D1; GLUT: glucose transporter; GSK3: glycogen synthase kinase 3; HER2: human epidermal growth factor receptor 2; IGF-1R: insulin like growth factor 1 receptor; JNK: Jun N-terminal kinase; P: protein; PAK: p21 activating kinase; PI3K: phosphoinositide 3-kinase; Ras: rat sarcoma virus; Src: sarcoma; TGF: transforming growth factor

\section{Modulation of estrogen-ER- $\alpha$-signaling pathway}

Under the natural photoperiod, melatonin is expected to be a regulator of reproduction in seasonally breeding animals [50]. It modulates the hypothalamic-pituitary-gonadal axis (HPGA) [51], resulting in the decrease of ovarian estrogen synthesis [25]. However, humans are not seasonal breeders and melatonin exercises some modulatory actions on steroidogenesis in human luteal cells [52, 53].

The early report indicated that melatonin downregulated the synthesis of sex steroids, particularly estrogen. Thus, melatonin has a negative impact on estrogen-signaling [54]. Melatonin suppressed estrogen-mediated proliferation of human breast cancer cells in in vitro system. Hill et al. [25, 34] suggested that melatonin regulates the estrogenic actions on breast and mammary tissue in three ways: (i) diminution of synthesis of sex steroids, including estrogens and reduction of their circulating levels; (ii) binding with ER- $\alpha$ as a selective ER modulator (SERM) to inhibit estrogen binding, nuclear translocation, DNA-binding, and transcriptional activation; (iii) decreasing the activity of the enzymes such as aromatase, sulfatase, and aldo-keto reductases (AKRs) involved in the synthesis of estrogens from cholesterol. Administration of melatonin might be a key inhibitor of breast cancer. The cell line study indicated that $1 \mathrm{nmol} / \mathrm{L}$ solution of melatonin can repress the proliferation of ER- $\alpha$-positive human breast cancer as well as suppression of the ER- $\alpha$ mRNA expression [25].

Melatonin is a powerful repressor of estrogen-induced ER- $\alpha$-dependent transcriptional activities. It inhibits several estrogen-induced mitogenic expressions and anti-apoptotic gene transcription including $B c l-2$. Alternatively, melatonin influences the expression of growth-inhibitory and pro-apoptotic genes like 
TGF- $\alpha$ and Bax [55]. Melatonin-Gai2 protein suppresses cAMP production, followed by a diminution of PKA levels, leading to impaired phosphorylation of serine-236 of the ER- $\alpha$. This PKA-sensitive site of ER- $\alpha$ plays a crucial role in the inhibition of ER- $\alpha$-dependent transcriptional activities [20,25]. Melatonin can couple with $\mathrm{CaM}$ and suppresses ER- $\alpha$-mediated functions by modulating the PKA-driven $\mathrm{Ca}^{2+} / \mathrm{CaM}^{2}$ pathway.

A chromatography-mediated immunoprecipitation study indicated that melatonin blocked 17- $\beta$ estradiol-mediated recruitment of CaM and p300 to the Cyc D1 promoter [25]. The absence of estrogenic activity shows the significant declining effects due to less recruitment of p300 to the Cyc D1 promoter. Reverse action had been observed within $1.5 \mathrm{~h}$ after administration of estrogen. The daily rhythm of estrogen peak arises in the early morning which is essential for the estrogenic activity [25]. Generally, plasma melatonin peak reaches 2 a.m. followed by the decreasing effect. Thus, estrogen levels begin to rise when the melatonin peak is in a downward step [56].

It was reported that dim light exposure at night (dLEN) hampers the melatonin functions and circadian signal. Circadian dysfunction induced the phosphorylation of the ER- $\alpha$ at Ser-118 and Ser-167 through the action of extracellular receptor kinase (ERK)-1 and ERK-2, cellular-Src (c-Src) kinase, and protein kinase B (Akt) [25, 49]. During dLEN, exogenous supplementation of melatonin significantly suppresses the phosphorylation of ER- $\alpha$. This evidence strongly supports the role of melatonin on the regulation of gene expression in human breast cancer cells via the actions of the MT1-ER- $\alpha$ receptor-specific mechanism. However, contradictory findings in relation to night shift work and the incidence of cancer are also available. The meta-analysis study revealed that the development of cancer is not influenced by fixed time work or rotational night shift work. In this concern, the negative result had also been obtained from Asian people. The risk of cancer was low in Asians compared to Americans and Europeans due to their distinct food habits, lifestyles, and gene pools [57].

\section{Expression of other NRs in human breast cancer cells by melatonin}

The decrease of ER- $\alpha$ expression also regulates the transcriptional activity of other steroid hormones/ NR super-family receptors. It is evident that melatonin can repress the ligand-induced expression of the glucocorticoid receptor (GR) and ROR- $\alpha$ in breast cancer cells $[25,58]$. Alternatively, melatonin can enhance the expression of other NRs, including retinoic acid X receptor alpha (RXR $\alpha$ ) and the retinoic acid receptor alpha $(\operatorname{RAR} \alpha)[25,59]$.

Dauchy et al. [60] reported that melatonin administration during dLEN-mediated circadian disruption induced the expression and phosphorylation of many kinases (Akt, ERK1/2, FAK, PKA, Src, etc.) that regulate the phosphorylation of NRs and other transcriptional factors (Ap-1, Elk-1, NF- $\kappa B$, STAT3, etc). This event clearly expresses the importance of melatonin in the regulation of gene expression in human breast cancer cells. Furthermore, administration of melatonin along with all-trans-retinoic acid (RXR $\alpha$ and RAR $\alpha$ ) in MCF-7 cells induced the rate of apoptosis, which is mediated by increased expression of pro-apoptotic protein Bax and downregulation of TGF- $\beta 1$ and Bcl-2 (anti-apoptotic protein) expression [61]. In addition, the combination of 9-cis retinoic acid and melatonin can inhibit the progression of $N$-nitroso- $N$-methyl urea (NMU)-induced breast tumors in rats [25,54]. In the presence of vitamin D, melatonin can promote vitamin D receptor (VDR) transcriptional activity and drive the MCF-7 breast tumor cells towards apoptosis [62, 63].

\section{Melatonin induces cytotoxicity in breast cancer cells}

The pharmacologic concentration of melatonin shows cytotoxic effects in breast cancer cells. The experimental reports revealed that physiologic concentrations of melatonin suppressed the in vitro proliferation of breast cancer cells by disrupting the cell cycle through the p21 or p53 pathway and induction of apoptosis [25]. Gurunathan et al. [64] reported that co-administration of melatonin and retinoic acid significantly increases the cytotoxicity and apoptosis in MCF-7 cells. The in vivo studies favor the melatonin-induced apoptotic rate in rat mammary tumors by increasing caspase-3 activity and DNA fragmentation [16,54]. Treatment of $1 \mathrm{nmol} / \mathrm{L}$ melatonin showed a sharp reduction in mouse double 
minute 2 (MDM2) that promotes ubiquitin ligase-mediated breakdown of p53 [25]. Down-regulation of MDM2 enhanced acetylation of p53 and increases the expression of p21 levels, leading to inhibition of the cell cycle progression and induction of p53-mediated apoptosis [65].

Numerous in vitro and in vivo studies on breast cancer reported that melatonin is less sensitive to the apoptotic effects when administered as a single agent. Applications of melatonin as an adjuvant with chemotherapeutic drugs potentially magnify the apoptotic effects $[49,66]$. The pharmacologic concentration of melatonin activates both intrinsic and extrinsic apoptotic pathways in cancer cells, specifically by increasing the p53/MDM2 ratio and down-regulating the Sirt1, which is a potent metabolic regulator $[25,67]$.

\section{Effects of melatonin on metabolism in tumor cells}

Tumor cells exhibit robust uptake of circulating glucose that converted to lactate through the classical glycolytic pathway (Warburg effect). This effect meets the energy demand in the cancer cells to accommodate fast-growing tumor biomass [68-70]. HIF-1 $\alpha$, Akt, and cellular-master regulator of cell cycle entry and proliferative metabolism (c-MYC) are the important signal transducing and transcriptional networks, which operate the Warburg effect to reprogram the metabolism in cancer cells for continuous proliferation [71, 72]. A high rate of glycolysis increases cell proliferation and survival properties in tumor biomass. Besides these, uptake of LA is the most critical step for breast tumor growth and cancer cell proliferation [73]. The study of the xenograft model had revealed that LA is metabolized to 13-hydroxyoctadecadienoic acid (13-HODE), which favors the metabolic alteration in breast cancer cells. Melatonin shows pleiotropic effects. Night-time melatonin maintains the proliferation and repairing of normal cells but diminishes the rate of tumor growth.

The LAN and circadian disruption promote the condition of a melatonin-deficient state. Moreover, LAN increases circulating IGF-1 levels and stimulates continuous expression of proliferating cell nuclear antigen (PCNA) in nude rats. LAN also induces Akt-dependent activation of phosphoinositide-dependent protein kinase 1 (PDK1), which facilitates the expression of the IGF-1R. Collectively, these effects accelerate tumor growth in tumor-bearing nude rats through the activation of IGF-1R/PDK1 signaling [74]. Therefore, chronic disruption of circadian equilibrium increases metabolic and proliferative activities. Moreover, melatonin regulates the circadian oscillations of tumor signaling factors such as Akt, cAMP, HIF-1 $\alpha$, LA metabolism, and the Warburg effect. dLEN crucially interrupted the circadian oscillations, leading to metabolic fluctuations and deregulation of allosteric feedback activity followed by impaired metabolism in human breast cancer cells [25,34].

\section{Effects of light exposure at night on melatonin secretion and breast cancer}

Epidemiological studies indicate a higher risk for certain types of cancer in night shift workers. The International Agency for Research on Cancer recommended night shift work probably carcinogenic (group 2A) to humans [57, 75]. LAN has an influencing effect on breast cancer. The incidence of breast cancer shows $73 \%$ higher in LAN exposed individuals compared to the unexposed group [76]. This finding is supported by the relationship between urinary melatonin excretion and the occurrence of breast cancer. An earlier study had indicated the low levels of urinary melatonin in human breast cancer patients [77]. Devore et al. [78] had indicated the relationship between urinary melatonin and the risk of breast cancer in postmenopausal women. They had included 1,354 postmenopausal women (nurses) and measured 6-sulfatoxymelatonin (excretory product of melatonin) from the first-morning spot urine. They reported that excretion of urinary melatonin had been associated with a lower risk of breast cancer in postmenopausal women. Elevated serum estradiol and low levels of urinary 6-sulfatoxymelatonin had been observed in postmenopausal women working at night that might be the pre-indicator of risk of breast cancer. However, this effect was not modified by the expression of the MT1 receptor in tumor cells [79-81].

The decreasing function of the pineal gland may amplify the risk of breast cancer by increasing exposure to circulating estrogens. Calcification of pinealocytes increases the incidence of breast cancer. Women who are taking chlorpromazine showed elevated levels of melatonin and lower rates of breast cancer [82]. Human ovarian cells express melatonin receptors that have a direct effect on ovarian estrogen synthesis and restrict 
hormone-sensitive breast cancer formation [17]. Richard Stevens [83] made a prognostic hypothesis that exposure to LAN in women had higher rates of breast cancer.

Industrialization, electrification, exposure to LAN and night shift work in the USA and other Western countries have decreased the pineal melatonin production and increased the risk of breast cancer [25, 49]. Melatonin production in the pineal gland is an extremely trustable output signal of the circadian clock. This signal is depressed by the duration, intensity, and wavelength of LAN [49, 84]. Rotating night-shift work advances the light exposure-induced circadian disruption and increases the risk of breast cancer [85]. Blask et al. [49] reported that isolated breast cancer cells increased cAMP levels, the expression of mitogen-activated protein kinase (MAPK), uptake of LA and its conversion to 13-HODE when the cells were perfused with blood taken from women exposed to dim light (0.2 lux) at night. Reverse results appeared with the perfusion of blood taken from women at dark night. The inhibitory effect of melatonin is receptor-mediated, and the blocking of receptors shows antagonistic effects [74]. Mao et al. [86] reported that the phosphorylation of the GSK3 $\beta$ enzyme is a crucial factor for breast cancer cell metabolism, proliferation, and survival in the tumor xenograft model. LAN depresses nocturnal pineal functions, followed by inhibition of GSK3 $\beta$ activation through phosphorylation of serine-473 and serine-9 [30].

Impaired melatonin levels at night activate PI3K/Akt pathway, epidermal growth factor receptor (EGFR)/HER2 pathway, RAS/MAPK/ERK pathway, the PAK-1, PI3K/Akt/pyruvate dehydrogenase kinase-1 (PDK-1), and ribosomal S6-kinase (RSK). Collectively, these enzymatic pathways can promote cancer cell proliferation, survival, metastasis, and drug resistance [25, 87]. Other signaling pathways, including cAMP, PKA, PK-C $\alpha$ and $\delta, c-S r c, F A K, C R E B, S T A T 3$, and NF- $\kappa B$ were activated in dLEN-induced low melatonin state [88]. Supplementation of melatonin in isolated tumor exhibits inhibition of these signaling pathways to suppress tumor cell proliferation and drug resistance properties [49].

Peripheral tissues, including the breast, also bear circadian clocks that are synchronized with the SCN. The normal circadian rhythm regulates the expression of clock genes (PER, Cry, BMAL1, Clock). Impaired expression of clock genes influences cancer development [89]. The products of clock genes are involved in the expression of p21, Cyc D, c-Myc, and Wee1 for the regulation of the cell cycle [90-92]. The period 2 (PER2) has been reported to be a tumor suppressor gene whose expression reduces the formation of a variety of tumors like breast, prostate, and lymphoma [89, 93]. Loss of PER2 may induce breast cancer. Decreasing PER2 gene expression by methylation or degradation of $P E R 2$ by casein-kinase- $1 \varepsilon$ promotes the development of breast cancer. Circadian dysfunction alters DNA methylation and expression of clock genes, including PER2 [89, 94]. Audia and Campbell [94] reported that melatonin may regulate epigenetic-induced gene expression and resist the progression of the tumor. Several reports indicated that clock genes are involved in the regulation of the cell cycle, DNA repair, cellular metabolism, oxidative stress, apoptotic response, inflammatory activity, and epithelial-mesenchymal transition. Circadian dysfunction and impaired melatonin alter the expression of clock genes, leading to the progression of cancer $[46,95,96]$.

\section{Role of melatonin in therapeutic strategies of breast cancer}

Resistance to chemotherapy and endocrine therapy is the most important obstacle for the successful treatment of breast cancer [97, 98]. Experimental evidence showed the link between activation of different types of pro-oncogenic tyrosine kinases and the development of resistance power against chemotherapeutic drugs as well as anti-estrogenic agents in breast cancer cells $[99,100]$. About $60-75 \%$ of breast cancer cells express progesterone receptor (PR) and ER- $\alpha$ that are used as a marker for the endocrine therapies, including ER- $\alpha$ modulators, such as tamoxifen [101, 102]. However, $40 \%$ of patients with ER- $\alpha$-positive breast tumors show inherent resistance to tamoxifen [103]. Anthracycline, such as doxorubicin, is commonly used as a chemotherapeutic drug for patients whose breast tumors are in metastatic stage or endocrine-resistant [104]. There are various types of mechanisms that make the cancerous cell to resist drugs or chemotherapies. The activation of numerous signaling pathways, including EGFR/HER2/MAPK/ ERK and PI3K/Akt enhances drug resistance capacity $[105,106]$. It was reported that the expression of various transcription factors and kinases are elevated in human breast cancer cell lines and in 
experimental breast tumor biopsy samples. These observations indicate the inherent capacity of resistance to anti-endocrine and chemotherapeutic agents [107]. The drug resistance properties are linked with the up-regulation of adenosine triphosphate (ATP)-binding cassette (ABC) transporter such as ABCB1, ABCC1, and $A B C G 2$ as well as drug-metabolizing enzymes; the results are decreased levels of active drug within the cancer cells [108]. It had found that exposure to dLEN enhances the expression of the ABC transporter-like ABCG2 that is termed as the breast cancer resistance protein. Breast cancer resistance protein involves the efflux of 4-hydroxy-tamoxifen (40H-Tam), and endoxifen [25]. Several in vitro studies proved that melatonin may increase the efficacy of tamoxifen and doxorubicin [54,64]. Melatonin alters the activity of ER- $\alpha$ through inhibition of kinase signaling pathways and increases the tamoxifen-mediated antagonistic effects on ER- $\alpha$. It also reduces the efflux of tamoxifen from breast tumor cells [54]. The tumor xenografts were extremely sensitive to the synergistic actions of melatonin and doxorubicin. Supplementation of melatonin suppresses the growth of the doxorubicin-resistance cancer cells $[25,109]$.

\section{Application of melatonin in the clinical trials for breast cancer treatment}

Melatonin has potential anti-cancer properties. But the results of clinical trials in human breast cancer therapy are insufficient, and it is not included in the treatment regimen [110]. However, some reports are available in the field of the clinical trial of melatonin. The studies indicated that the cancer patients taking $20 \mathrm{mg}$ of melatonin gave better clinical outcomes. The beneficial effects were remission of tumor volume and decreased rate of mortality [111-113]. It was observed that sleep problem is a great challenge in breast cancer survivors, even after the completion of anti-cancer therapy. Li et al. [114] reported that the first cycle of breast cancer chemotherapy disrupted the sleep-wake cycle, sleep quality, cognitive functions, and melatonin secretion. These are appeared as the side effects of breast cancer treatment. Application of $20 \mathrm{mg}$ melatonin as an adjuvant prior to first cycle chemotherapy of breast cancer in a randomized, double-blinded, placebo-controlled trial with 36 participants showed improvement of cognitive performance, immediate and delayed episodic memory, sleep quality, and depressive symptoms [115]. Previously, a randomized, double-blind, and placebo-controlled trial of melatonin had also been conducted on the patients undergoing breast cancer surgery. The application of $6 \mathrm{mg}$ oral melatonin for 3 months significantly reduced the risk of depressive symptoms [116].

Estradiol levels, IGF-1 concentration, insulin-like growth factor-binding protein 3 (IGFBP-3) expression, and the IGF-1/IGFBP-3 ratio are regarded as the biomarkers of breast cancer. Schernhammer et al. [117] had evaluated whether melatonin has an effect on biomarkers or not. They performed a randomized, double-blind, and placebo-controlled study on 95 postmenopausal women who had a prior history of breast cancer report in different sage (0-III). These patients had completed the anti-cancer treatment (including hormonal therapy). A course of $3 \mathrm{mg}$ of melatonin per day for 4 months had been given orally to the 48 patients and a placebo had been provided to the rest of the members (47 patients). The outcome of the study had revealed that melatonin did not influence circulating estradiol, IGF-1, IGFBP-3 levels, and IGF-1/ insulin-like growth factor-binding protein (IGBP) ratio after the short-term course of melatonin treatment. Chen et al. [118] had conducted the same study as performed by Schernhammer et al. [117] to establish the role of melatonin on the improvement of sleep quality. Finally, they reported that melatonin-experienced patients showed significant improvement in sleep quality and related parameters. A good result had been observed in Pittsburgh sleep quality index (PSQI) score compared to placebo-controlled patients.

A clinical study had been conducted on 167 patients with TNBC. The outcome of the study had indicated that $48 \%$ of the TNBC patients showed MT1-negative while only 11\% TNBC exhibited MT1-positive. The MT1-positive TNBC patients were in the early stage of breast cancer with a smaller volume of tumor size. The MT1-negative TNBC patients were at high risk of cancer progression. The progression-free survival (PFS) rate was also low. The overall survival ratio compared to PFS was significantly decreased in MT1-negative TNBC [38]. Simultaneous use of somatostatin, melatonin, retinoid, vitamin D3, and cyclophosphamide (prolactin inhibitor) has been made on 20 women who have breast cancer. The rate of response of the 
treatment is about $75 \%$ (55\% complete response and $20 \%$ partial response) while $71 \%$ of metastatic patients exhibit overall survival capacity [119].

\section{Conclusion}

Melatonin acts as a potent anti-cancer agent. The actions of melatonin in breast cancer are driven by regulating the different molecular pathways related to growth inhibition and pro-apoptotic effects. Exposure to LAN, shift/might work, chronic jet lag, and sleep disorder hamper melatonin synthesis and lower the night-time melatonin peak. Epidemiological studies regarding breast cancer indicated that women working at night or swing shifts were vulnerable to the development of breast cancer. The prospective studies indicated the association between a low level of urinary melatonin and the incidence of breast cancer. Melatonin exerts anti-estrogenic and anti-inflammatory, immune-modulating, and anti-mitogenic actions. Supplemental melatonin shows oncostatic effects in breast cancer. MT1 receptors are the key factor for cytostatic and pro-apoptotic activity. Several possibilities regarding melatonin's actions as an anti-cancer agent in breast treatment are showing positive impacts and have a prospective future as a therapeutic agent in breast cancer treatment. Melatonin increases the efficacy of chemotherapeutic drugs in the treatment of breast cancer. On the other hand, supplementation of melatonin at nontoxic pharmacological doses in breast cancer patients gives financial benefit due to its low cost and wide accessibility. Finally, it can be said that further research and prospective clinical trials will open a new avenue for the use of melatonin in the treatment of breast cancer.

\section{Abbreviations}

$\mathrm{ABC}$ : adenosine triphosphate-binding cassette

Akt: protein kinase B

Bax: B-cell lymphoma-2 associated X protein

Bcl: B-cell lymphoma

CaM: calmodulin

cAMP: cyclic adenosine monophosphate

CREB: cyclic adenosine monophosphate-responsive element-binding protein

Cyc D1: cyclin D1

dLEN: dim light exposure at night

ER- $\alpha$ : estrogen receptor- $\alpha$

ERK: extracellular receptor kinase

G-protein: guanosine triphosphate-binding protein

GSK3: glycogen synthase kinase 3

HER2: human epidermal growth factor receptor 2

HIF-1 $\alpha$ : hypoxia-inducible factor $1 \alpha$

IGF-1R: insulin like growth factor 1 receptor

IGFBP-3: insulin-like growth factor-binding protein 3

LA: linoleic acid

LAN: light-at-night

MAPK: mitogen-activated protein kinase

MDM2: mouse double minute 2

MT1: melatonin receptor 1

NRs: nuclear receptors

PER2: period 2

PI3K: phosphoinositide 3-kinase 
PKA: protein kinase A

ROR: retinoid-related orphan receptor

Src: sarcoma

TGF: transforming growth factor

TNBC: triple-negative breast cancers

\section{Declarations}

\section{Acknowledgments}

The authors are grateful to Midnapore College, Midnapore, West Bengal, India, for providing all kinds of facilities (infrastructural, computer and internet) to prepare this manuscript.

\section{Author contributions}

Dr. NKD started literature survey and collected the relevant papers. He had prepared the draft of the manuscript. Dr. SS had supervised the work. He had involved in the writing and correction of the manuscript. At the finishing stage, he had drawn all the pictures and given the final shape of the manuscript.

\section{Conflicts of interest}

The authors declare that they are no conflicts of interest.

\section{Ethical approval}

Not applicable.

\section{Consent to participate}

Not applicable.

\section{Consent to publication}

Not applicable.

Availability of data and materials

Not applicable.

\section{Funding}

Not applicable.

\section{Copyright}

(C) The Author(s) 2022.

\section{References}

1. Lerner AB, Case JD, Takahashi Y. Isolation of melatonin and 5-methoxyindole-3-acetic acid from bovine pineal glands. J Biol Chem. 1960;235:1992-7.

2. Berson DM, Dunn FA, Takao M. Phototransduction by retinal ganglion cells that set the circadian clock. Science. 2002;295:1070-3.

3. Hastings $\mathrm{MH}$, Reddy AB, Maywood ES. A clockwork web: circadian timing in brain and periphery, in health and disease. Nat Rev Neurosci. 2003;4:649-61.

4. Stehle JH, von Gall C, Korf HW. Melatonin: a clock-output, a clock-input. J Neuroendocrinol. 2003;15:383-9.

5. Kohsaka A, Bass J. A sense of time: how molecular clocks organize metabolism. Trends Endocrinol Metab. 2007;18:4-11. 
6. Truong T, Liquet B, Menegaux F, Plancoulaine S, Laurent-Puig P, Mulot C, et al. Breast cancer risk, nightwork, and circadian clock gene polymorphisms. Endocr Relat Cancer. 2014;21:629-38.

7. Gnocchi D, Bruscalupi G. Circadian rhythms and hormonal homeostasis: pathophysiological implications. Biology (Basel). 2017;6:10.

8. Szkiela M, Kusideł E, Makowiec-Dąbrowska T, Kaleta D. Night shift work-a risk factor for breast cancer. Int J Environ Res Public Health. 2020;17:659.

9. Samanta S. Melatonin: an endogenous miraculous indolamine, fights against cancer progression. J Cancer Res Clin Oncol. 2020;146:1893-922.

10. Rodgers KM, Udesky JO, Rudel RA, Brody JG. Environmental chemicals and breast cancer: an updated review of epidemiological literature informed by biological mechanisms. Environ Res. 2018;160:152-82.

11. Grant SG, Melan MA, Latimer JJ, Witt-Enderby PA. Melatonin and breast cancer: cellular mechanisms, clinical studies and future perspectives. Expert Rev Mol Med. 2009;11:e5.

12. Kubatka P, Zubor P, Busselberg D, Kwon TK, Adamek M, Petrovic D, et al. Melatonin and breast cancer: evidences from preclinical and human studies. Crit Rev Oncol Hematol. 2018;122:133-43.

13. Samanta S. Physiological and pharmacological perspectives of melatonin. Arch Physiol Biochem. 2020; [Epub ahead of print].

14. Falcon J. Nocturnal melatonin synthesis: how to stop it. Endocrinology. 2007;148:1473-4.

15. Brainard GC, Hanifin JP, Greeson JM, Byrne B, Glickman G, Gerner E, et al. Action spectrum for melatonin regulation in humans: evidence for a novel circadian photoreceptor. J Neurosci. 2001;21:6405-12.

16. Li Y, Li S, Zhou Y, Meng X, Zhang JJ, Xu DP, et al. Melatonin for the prevention and treatment of cancer. Oncotarget. 2017;8:39896-921.

17. Schettig R, Sears T, Klein M, Tan-Lim R, Matthias R, Aussems C, et al. Melatonin: a powerful integrative adjunctive agent for oncology. J Cancer Ther. 2020;11:571-96.

18. Rondanelli M, Faliva MA, Perna S, Antoniello N. Update on the role of melatonin in the prevention of cancer tumorigenesis and in the management of cancer correlates, such as sleep-wake and mood disturbances: review and remarks. Aging Clin Exp Res. 2013;25:499-510.

19. Acuña-Castroviejo D, Escames G, Venegas C, Díaz-Casado ME, Lima-Cabello E, López LC, et al. Extrapineal melatonin: sources, regulation, and potential functions. Cell Mol Life Sci. 2014;71:2997-3025.

20. Lai L, Yuan L, Chen Q, Dong C, Mao L, Rowan B, et al. The Galphai and Galphaq proteins mediate the effects of melatonin on steroid/thyroid hormone receptor transcriptional activity and breast cancer cell proliferation. J Pineal Res. 2008;45:476-88.

21. Rivas Santisteban R, Reyes-Resina I, Raïch I, Pintor JJ, Alkozi HA, Navarro Brugal G, et al. Specificity and nanomolar potency of melatonin on G-protein coupled melatonin MT1 and MT2 receptors expressed in HEK-293T human embryo kidney cells. Melatonin Research. 2019;2:121-31.

22. Emet M, Ozcan H, Ozel L, Yayla M, Halici Z, Hacimuftuoglu A. A review of melatonin, its receptors and drugs. Eurasian J Med. 2016;48:135-41.

23. Li DY, Smith DG, Hardeland R, Yang MY, Xu HL, Zhang L, et al. Melatonin receptor genes in vertebrates. Int J Mol Sci. 2013;14:11208-23.

24. Dinet V, Korf HW. Impact of melatonin receptors on pCREB and clock-gene protein levels in the murine retina. Cell Tissue Res. 2007;330:29-34.

25. Hill SM, Belancio VP, Dauchy RT, Xiang S, Brimer S, Mao L, et al. Melatonin: an inhibitor of breast cancer. Endocr Relat Cancer. 2015;22:R183-204.

26. Schuster C. Sites and mechanisms of action of melatonin in mammals: the MT1 and MT2 receptors. J Soc Biol. 2007;201:85-96. French. 
27. Pandi-Perumal SR, Trakht I, Srinivasan V, Spence DW, Maestroni GJM, Zisapel N, et al. Physiological effects of melatonin: role of melatonin receptors and signal transduction pathways. Prog Neurobiol. 2008;85:335-53.

28. Witt-Enderby PA, Bennett J, Jarzynka MJ, Firestine S, Melan MA. Melatonin receptors and their regulation: biochemical and structural mechanisms. Life Sci. 2003;72:2183-98.

29. Jockers R, Maurice P, Boutin JA, Delagrange P. Melatonin receptors, heterodimerization, signal transduction and binding sites: what's new? Br J Pharmacol. 2008;154:1182-95.

30. Liu J, Clough SJ, Hutchinson AJ, Adamah-Biassi EB, Popovska-Gorevski M, Dubocovich ML. MT1 and MT2 melatonin receptors: a therapeutic perspective. Annu Rev Pharmacol Toxicol. 2016;56:361-83.

31. Cecon E, Oishi A, Jockers R. Melatonin receptors: molecular pharmacology and signalling in the context of system bias. Br J Pharmacol. 2018;175:3263-80.

32. Jin Y, Choi YJ, Heo K, Park SJ. Melatonin as an oncostatic molecule based on its anti-aromatase role in breast cancer. Int J Mol Sci. 2021;22:438.

33. Hill SM, Frasch T, Xiang S, Yuan L, Duplessis T, Mao L. Molecular mechanisms of melatonin anticancer effects. Integr Cancer Ther. 2009;8:337-46.

34. Hill SM, Blask DE, Xiang S, Yuan L, Mao L, Dauchy RT, et al. Melatonin and associated signaling pathways that control normal breast epithelium and breast cancer. J Mammary Gland Biol Neoplasia. 2011;16:235-45.

35. Nooshinfar E, Safaroghli-Azar A, Bashash D, Akbari ME. Melatonin, an inhibitory agent in breast cancer. Breast Cancer. 2017;24:42-51.

36. Al-Mahmood S, Sapiezynski J, Garbuzenko OB, Minko T. Metastatic and triple-negative breast cancer: challenges and treatment options. Drug Deliv Transl Res. 2018;8:1483-507.

37. Oprea-Ilies G, Haus E, Sackett-Lundeen L, Liu Y, McLendon L, Busch R, ET AL. Expression of melatonin receptors in triple negative breast cancer (TNBC) in African American and Caucasian women: relation to survival. Breast Cancer Res Treat. 2013;137:677-87.

38. Wen YC, Lin YW, Chu CY, Yang YC, Yang SF, Liu YF, et al. Melatonin-triggered post-transcriptional and post-translational modifications of ADAMTS1 coordinately retard tumorigenesis and metastasis of renal cell carcinoma. J Pineal Res. 2020;69:e12668.

39. Dehdashtian E, Mehrzadi S, Yousefi B, Hosseinzadeh A, Reiter RJ, Safa M, et al. Diabetic retinopathy pathogenesis and the ameliorating effects of melatonin; involvement of autophagy, inflammation and oxidative stress. Life Sci. 2018;193:20-33.

40. Carrillo-Vico A, Lardone PJ, Álvarez-Sánchez N, Rodríguez-Rodríguez A, Guerrero JM. Melatonin: buffering the immune system. Int J Mole Sci. 2013;14:8638-83.

41. Talib WH. Melatonin and cancer hallmarks. Molecules. 2018;23:518.

42. Reiter RJ, Rosales-Corral SA, Tan DX, Acuna-Castroviejo D, Qin L, Yang SF, et al. Melatonin, a full service anti-cancer agent: inhibition of initiation, progression and metastasis. Int J Mol Sci. 2017;18:843.

43. Tengattini S, Reiter RJ, Tan DX, Terron MP, Rodella LF, Rezzani R. Cardiovascular diseases: protective effects of melatonin. J Pineal Res. 2008;44:16-25.

44. Bhattacharya S, Patel KK, Dehari D, Agrawal AK, Singh S. Melatonin and its ubiquitous anticancer effects. Mol Cell Biochem. 2019;462:133-55.

45. Mehrzadi S, Pourhanifeh MH, Mirzaei A, Moradian F, Hosseinzadeh A. An updated review of mechanistic potentials of melatonin against cancer: pivotal roles in angiogenesis, apoptosis, autophagy, endoplasmic reticulum stress and oxidative stress. Cancer Cell Int. 2021;21:188.

46. Bonmati-Carrion MA, Tomas-Loba A. Melatonin and cancer: a polyhedral network where the source matters. Antioxidants (Basel). 2021;10:210. 
47. Santoro R, Mori F, Marani M, Grasso G, Cambria MA, Blandino G, et al. Blockage of melatonin receptors impairs p53-mediated prevention of DNA damage accumulation. Carcinogenesis. 2013;34:1051-61.

48. Johnston SRD, Dowsett M. Aromatase inhibitors for breast cancer: lessons from the laboratory. Nat Rev Cancer. 2003;3:821-31.

49. Blask DE, Dauchy RT, Dauchy EM, Mao L, Hill SM, Greene MW, et al. Light exposure at night disrupts host/ cancer circadian regulatory dynamics: impact on the Warburg effect, lipid signalling and tumour growth prevention. PLoS One. 2014;9:e102776.

50. viviD D, Bentley GE. Seasonal reproduction in vertebrates: melatonin synthesis, binding, and functionality using Tinbergen's four questions. Molecules. 2018;23:652.

51. Talpur HS, Chandio IB, Brohi RD, Worku T, Rehman Z, Bhattarai D, et al. Research progress on the role of melatonin and its receptors in animal reproduction: a comprehensive review. Reprod Domest Anim. 2018;53:831-49.

52. Luboshitzky R, Lavie P. Melatonin and sex hormone interrelationships-a review. J Pediatr Endocrinol Metab. 1999;12:355-62.

53. Olcese JM. Melatonin and female reproduction: an expanding universe. Front Endocrinol (Lausanne). 2020;11:85.

54. Menéndez-Menéndez J, Martínez-Campa C. Melatonin: an anti-tumor agent in hormone-dependent cancers. Int J Endocrinol. 2018;2018:3271948.

55. Ram PT, Dai J, Yuan L, Dong C, Kiefer TL, Lai L, et al. Involvement of the mt1 melatonin receptor in human breast cancer. Cancer Lett. 2002;179:141-50.

56. Brennan R, Jan JE, Lyons CJ. Light, dark, and melatonin: emerging evidence for the importance of melatonin in ocular physiology. Eye (Lond). 2007;21:901-8.

57. Dun A, Zhao X, Jin X, Wei T, Gao X, Wang Y, et al. Association between night-shift work and cancer risk: updated systematic review and meta-analysis. Front Oncol. 2020;10:1006. Erratum in: Front Oncol. 2020;10:1580.

58. Presman DM, Hoijman E, Ceballos NR, Galigniana MD, Pecci A. Melatonin inhibits glucocorticoid receptor nuclear translocation in mouse thymocytes. Endocrinology. 2006;147:5452-9.

59. Hardeland R. Melatonin and retinoid orphan receptors: demand for new interpretations after their exclusion as nuclear melatonin receptors. Melatonin Research. 2018;1:78-93.

60. Dauchy RT, Xiang S, Mao L, Brimer S, Wren MA, Yuan L, et al. Circadian and melatonin disruption by exposure to light at night drives intrinsic resistance to tamoxifen therapy in breast cancer. Cancer Res. 2014;74:4099-110.

61. Eck KM, Yuan L, Duffy L, Ram PT, Ayettey S, Chen I, et al. A sequential treatment regimen with melatonin and all-trans retinoic acid induces apoptosis in MCF-7 tumour cells. Br J Cancer. 1998;77:2129-37.

62. Rana P. MELO-D: antiproliferative effects of melatonin and vitamin D in breast cancer. J Clin Oncol. 2014;32:TPS1616.

63. Proietti S, Cucina A, D’Anselmi F, Dinicola S, Pasqualato A, Lisi E, et al. Melatonin and vitamin D3 synergistically down-regulate Akt and MDM2 leading to TGF $\beta$-1-dependent growth inhibition of breast cancer cells. J Pineal Res. 2011;50:150-8.

64. Gurunathan S, Qasim M, Kang MH, Kim JH. Role and therapeutic potential of melatonin in various type of cancers. Onco Targets Ther. 2021;14:2019-52.

65. Proietti S, Cucina A, Dobrowolny G, D’Anselmi F, Dinicola S, Masiello MG, et al. Melatonin down-regulates MDM2 gene expression and enhances p53 acetylation in MCF-7 cells. J Pineal Res. 2014;57:120-9.

66. Talib WH, Alsayed AR, Abuawad A, Daoud S, Mahmod AI. Melatonin in cancer treatment: current knowledge and future opportunities. Molecules. 2021;26:2506. 
67. Alonso-González C, González A, Menéndez-Menéndez J, Martínez-Campa C, Cos S. Melatonin as a radio-sensitizer in cancer. Biomedicines. 2020;8:247.

68. Warburg 0. Über den stoffwechsel der carcinomzelle. Naturwissenschaften. 1924;12:1131-7. German.

69. Liberti MV, Locasale JW. The Warburg effect: how does it benefit cancer cells? Trends Biochemi Sci. 2016;41:211-8.

70. Samanta S, Dassarma B, Jana S, Rakshit S, Saha SA. Hypoxia inducible factor-1 (HIF-1) and cancer progression: a comprehensive review. Indian J Cancer Edu Res. 2018;6:94-109.

71. Schiliro C, Firestein BL. Mechanisms of metabolic reprogramming in cancer cells supporting enhanced growth and proliferation. Cells. 2021;10:1056.

72. Tarrado-Castellarnau M, de Atauri P, Cascante M. Oncogenic regulation of tumor metabolic reprogramming. Oncotarget. 2016;7:62726-53.

73. Nagarajan SR, Butler LM, Hoy AJ. The diversity and breadth of cancer cell fatty acid metabolism. Cancer Metab. 2021;9:2.

74. Wu J, Dauchy RT, Tirrell PC, Wu SS, Lynch DT, Jitawatanarat P, et al. Light at night activates IGF-1R/ PDK1 signaling and accelerates tumor growth in human breast cancer xenografts. Cancer Res. 2011;71:2622-31.

75. Garde AH, Begtrup L, Bjorvatn B, Bonde JP, Hansen J, Hansen ÅM, et al. How to schedule night shift work in order to reduce health and safety risks. Scand J Work Environ Health. 2020;46:557-69.

76. Kloog I, Haim A, Stevens RG, Barchana M, Portnov BA. Light at night co-distributes with incident breast but not lung cancer in the female population of Israel. Chronobiol Int. 2008;25:65-81.

77. Bartsch C, Bartsch H, Jain AK, Laumas KR, Wetterberg L. Urinary melatonin levels in human breast cancer patients. J Neural Transm. 1981;52:281-94.

78. Devore EE, Warner ET, Eliassen AH, Brown SB, Beck AH, Hankinson SE, et al. Urinary melatonin in relation to postmenopausal breast cancer risk according to melatonin 1 receptor status. Cancer Epidemiol Biomark Prev. 2017;26:413-9.

79. Nagata C, Nagao Y, Yamamoto S, Shibuya C, Kashiki Y, Shimizu H. Light exposure at night, urinary 6-sulfatoxymelatonin, and serum estrogens and androgens in postmenopausal Japanese women. Cancer Epidemiol Biomark Prev. 2008;17:1418-23.

80. Gómez-Acebo I, Dierssen-Sotos T, Papantoniou K, García-Unzueta MT, Santos-Benito MF, Llorca J. Association between exposure to rotating night shift versus day shift using levels of 6-sulfatoxymelatonin and cortisol and other sex hormones in women. Chronobiol Int. 2015;32:128-35.

81. Papantoniou K, Castaño-Vinyals G, Espinosa A, Aragonés N, Pérez-Gómez B, Ardanaz E, et al. Breast cancer risk and night shift work in a case-control study in a Spanish population. Eur J Epidemiol. 2016;31:867-78.

82. Cohen M, Lippman M, Chabner B. Role of pineal gland in aetiology and treatment of breast cancer. Lancet. 1978;2:814-6.

83. Stevens RG. Light-at-night, circadian disruption and breast cancer: assessment of existing evidence. Int J Epidemiol. 2009;38:963-70.

84. Rüger M, St Hilaire MA, Brainard GC, Khalsa SB, Kronauer RE, Czeisler CA, et al. Human phase response curve to a single $6.5 \mathrm{~h}$ pulse of short-wavelength light. J Physiol. 2013;591:353-63.

85. Wegrzyn LR, Tamimi RM, Rosner BA, Brown SB, Stevens RG, Eliassen AH, et al. Rotating night-shift work and the risk of breast cancer in the nurses' health studies. Am J Epidemiol. 2017;186:532-40.

86. Mao L, Dauchy RT, Blask DE, Slakey LM, Xiang S, Yuan L, et al. Circadian gating of epithelial-to-mesenchymal transition in breast cancer cells via melatonin-regulation of GSK3 $\beta$. Mol Endocinol. 2012;26:1808-20.

87. Roskoski R Jr. The ErbB/HER family of protein-tyrosine kinases and cancer. Pharmacol Res. 2014;79:34-74. 
88. Bessone MID, Berardi DE, Campodónico PB, Todaro LB, Lothstein L, de Kier Joffé EDB, et al. Involvement of PKC delta (PKC $\delta$ ) in the resistance against different doxorubicin analogs. Breast Cancer Res Treat. 2011;126:577-87.

89. Li HX. The role of circadian clock genes in tumors. Onco Targets Ther. 2019;12:3645-60.

90. Lee Y, Lahens NF, Zhang S, Bedont J, Field JM, Sehgal A. G1/S cell cycle regulators mediate effects of circadian dysregulation on tumor growth and provide targets for timed anticancer treatment. PLoS Biol. 2019;17:e3000228.

91. Fu L, Kettner NM. The circadian clock in cancer development and therapy. Prog Mol Biol Transl Sci. 2013;119:221-82.

92. Farshadi E, van Der Horst GTj, Chaves I. Molecular Links between the circadian clock and the cell cycle. J Mol Biol. 2020;432:3515-24.

93. Broadberry E, McConnell J, Williams J, Yang N, Zindy E, Leek A, et al. Disrupted circadian clocks and altered tissue mechanics in primary human breast tumours. Breast Cancer Res. 2018;20:125.

94. Audia JE, Campbell RM. Histone modifications and cancer. Cold Spring Harb Perspect Biol. 2016;8:a019521.

95. Patel SA, Kondratov RV. Clock at the core of cancer development. Biology (Basel). 2021;10:150.

96. de Almeida Chuffa LG, Seiva FRF, Cucielo MS, Silveira HS, Reiter RJ, Lupi LA. Clock genes and the role of melatonin in cancer cells: an overview. Melatonin Research. 2019;2:133-57.

97. Bukowski K, Kciuk M, Kontek R. Mechanisms of multidrug resistance in cancer chemotherapy. Int J Mo Sci. 2020;21:3233.

98. Ji X, Lu Y, Tian H, Meng X, Wei M, Cho WC. Chemo-resistance mechanisms of breast cancer and their countermeasures. Biomed Pharmacother. 2019;114:108800.

99. Luque-Bolivar A, Pérez-Mora E, Villegas VE, Rondón-Lagos M. Resistance and overcoming resistance in breast cancer. Breast Cancer (Dove Med Press). 2020;12:211-29.

100. Si W, Shen J, Zheng H, Fan W. The role and mechanisms of action of microRNAs in cancer drug resistance. Clin Epigenetics. 2019;11:25.

101. Huang H, Zhou J, Chen H, Li J, Zhang C, Jiang X, et al. The immunomodulatory effects of endocrine therapy in breast cancer. J Exp Clin Cancer Res. 2021;40:19.

102. Louie MC, Sevigny MB. Steroid hormone receptors as prognostic markers in breast cancer. Am J Cancer Res. 2017;7:1617-36.

103. Belachew EB, Sewasew DT. Molecular mechanisms of endocrine resistance in estrogen-positive breast cancer. Front Endocrinol (Lausanne). 2021;12:599586.

104. Wahba HA, El-Hadaad HA. Current approaches in treatment of triple-negative breast cancer. Cancer Biol Med. 2015;12:106-16.

105. Wahdan-Alaswad R, Liu B, Thor AD. Targeted lapatinib anti-HER2/ErbB2 therapy resistance in breast cancer: opportunities to overcome a difficult problem. Cancer Drug Resist. 2020;3:179-98.

106. Lee S, Rauch J, Kolch W. Targeting MAPK signaling in cancer: mechanisms of drug resistance and sensitivity. Int J Mol Sci. 2020;21:1102.

107. Piggott L, Silva A, Robinson T, Santiago-Gómez A, Simões BM, Becker M, et al. Acquired resistance of ER-positive breast cancer to endocrine treatment confers an adaptive sensitivity to TRAIL through posttranslational downregulation of c-FLIP. Clin Cancer Res. 2018;24:2452-63.

108. Wang X, Zhang H, Chen X. Drug resistance and combating drug resistance in cancer. Cancer Drug Resist. 2019;2:141-60.

109. Armando RG, Mengual Gómez DL, Gomez DE. New drugs are not enough-drug repositioning in oncology: an update. Int J Oncol. 2020;56:651-84. 
110. Kong X, Gao R, Wang Z, Wang X, Fang Y, Gao J, et al. Melatonin: a potential therapeutic option for breast cancer. Trends Endocrinol Metab. 2020;31:859-71.

111. Lissoni P. Biochemotherapy with standard chemotherapies plus the pineal hormone melatonin in the treatment of advanced solid neoplasms. Pathol Biol (Paris). 2007;55:201-4.

112. Sookprasert A, Johns NP, Phunmanee A, Pongthai P, Cheawchanwattana A, Johns J, et al. Melatonin in patients with cancer receiving chemotherapy: a randomized, double-blind, placebo-controlled trial. Anticancer Res. 2014;34:7327-37.

113. Rasmussen CL, Klee Olsen M, Thit Johnsen A, Aagaard Petersen M, Lindholm H, Andersen L, et al. Effects of melatonin on physical fatigue and other symptoms in patients with advanced cancer receiving palliative care: a double-blind placebo-controlled crossover trial. Cancer. 2015;121:3727-36.

114. Li W, Kwok CCH, Chan DCW, Ho AWY, Ho CS, Zhang J, et al. Disruption of sleep, sleep-wake activity rhythm, and nocturnal melatonin production in breast cancer patients undergoing adjuvant chemotherapy: prospective cohort study. Sleep Med. 2019;55:14-21.

115. Palmer ACS, Zortea M, Souza A, Santos V, Biazus JV, Torres ILS, et al. Clinical impact of melatonin on breast cancer patients undergoing chemotherapy; effects on cognition, sleep and depressive symptoms: a randomized, double-blind, placebo-controlled trial. PLoS One. 2020;15:e0231379.

116. Hansen MV, Andersen LT, Madsen MT, Hageman I, Rasmussen LS, Bokmand S, et al. Effect of melatonin on depressive symptoms and anxiety in patients undergoing breast cancer surgery: a randomized, double-blind, placebo-controlled trial. Breast Cancer Res Treat. 2014;145:683-95.

117. Schernhammer ES, Giobbie-Hurder A, Gantman K, Savoie J, Scheib R, Parker LM, et al. A randomized controlled trial of oral melatonin supplementation and breast cancer biomarkers. Cancer Causes Control. 2012;23:609-16.

118. Chen WY, Giobbie-Hurder A, Gantman K, Savoie J, Scheib R, Parker LM, et al. A randomized, placebo-controlled trial of melatonin on breast cancer survivors: impact on sleep, mood, and hot flashes. Breast Cancer Res Treat. 2014;145:381-8.

119. Di Bella G, Mascia F, Ricchi A, Colori B. Evaluation of the safety and efficacy of the first-line treatment with somatostatin combined with melatonin, retinoids, vitamin D3, and low doses of cyclophosphamide in 20 cases of breast cancer: a preliminary report. Neuro Endocrinol Lett. 2013;34:660-8. 